\title{
Revolutionizing Maghrebi Art to Move Toward a Cultural Identity
}

ALI HAIDER

December 9, 2016 
The Maghreb, or North Africa west of Egypt, has encountered countless revolutions since the early 1950's, such as the Algerian War of Independence from 1954 to 1962, the Moroccan protests against King Mohammed VI in 2012, the Tunisian Revolution which forced the exit of President Zine el-Abidine Ben Ali after twenty three years, and the Libyan Civil War in which the dictator Muammar Gadhafi was executed by rebels, a conflict that started in 2011 and still lives on. The steady rise in these political revolts was not simply a rise to sovereignty, however; these revolutions and wars devastated families who could no longer continue their businesses and lives in their homelands, pushing the large-scale diaspora of Maghrebi people into Europe. After years of attempting to assimilate into European communities, Maghrebi immigrants and refugees have been left on their own to discover where they come from and who they identify as. Pushed out of their homes into more unwelcoming territory, they have founded a culture of their own through artistic expression. In a worldwide exhibition tour called Memory, Place, Desire: Contemporary Art of the Maghreb and Maghrebi Diaspora, artists conceive a culture of expression out of the conflicted emotions arising from their immigration. The combination of various elements of different Maghrebi artists', scholars' and writers' work—such as Tahar Ben Jelloun's The Happy Marriage and Bouchra Khalili's Mapping Journey Project_embodies collective feelings of displacement, nostalgia, guilt, and loss of identity.

The worldwide exhibit serves the primary purpose of demonstrating the ways in which Maghrebi immigrants have been displaced. Through their teaching of the history of war and political turmoil, the artists manipulate environments around the pieces in order to elicit the feelings of displacement within the viewers themselves. Bouchra Khalili, for example, manipulates her environment in The Mapping Journey Project in order to make people feel lost, just as a Maghrebi immigrant or refugee would. Television screens are scattered across a pitch black room, each screen playing a different clip of someone drawing his or her journey to Europe on a map, highlighting borders that he or she had to cross and dabbing dotsat points on the map to describe their encounters with local police or places where he or she temporarily worked. The testifiers pass through multiple countries, stopping in places like Sicily, Naples, Athens, and Istanbul, places where no language is remotely similar to the previous country's or city's language. Diana Nawi writes how, in addition to her Mapping Journey Project, Khalili emphasizes the language barriers between the countries traveled through in her project Constellations. Khalili draws the lines from the maps as constellations and demonstrates the immigrants' struggles with adapting to multiple cultures and dialects, as not only do dialects vary across borders within North Africa, but completely differ from one another in European countries like Italy, Greece and Spain. The dark room, the multiple screens, and the narrators' storytelling make viewers uncomfortable while helping them understand what it feels like to be directed by a force that is not themselves, embodying the feelings of displacement that live in the psyches of Maghrebi immigrants.

Driss Ouadahi provides the antithesis to Bouchra Khalili's piece. While Khalili's Mapping Journey Project displays the constant movement of Maghrebi immigrants, Ouadahi's oil paintings such as Toutes Directions, Exit, and Underground Path depict the constant feelings of internment they face. These paintings portray large architectural structures similar to suburban architecture in countries like France. In an interview with Rachida Triki, he explains his motives for his paintings about urban landscapes, saying,

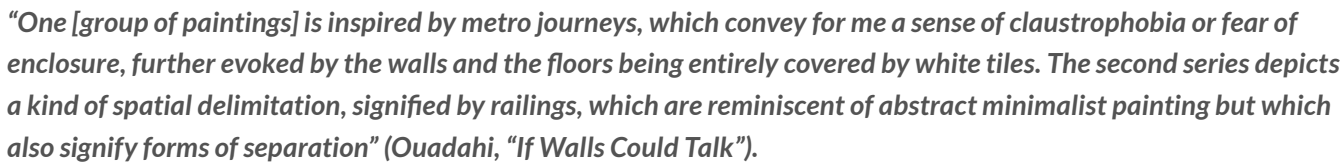

The feelings of claustrophobia and separation are evident throughout his paintings. In one group, Ouadahi paints tall buildings reminiscent of suburban buildings where immigrants live. He leaves little to no space in between the buildings in order to elicit a claustrophobic response from viewers. In another group, he paints a broken chain-linked fence meant to keep immigrants out of Europe. By painting a hole in the fence that is meant to be a symbol of immigrants' separation from their families and national identities, Ouadahi pushes them to break the barriers between European and Maghrebi thought in order to reach a "transcended space." He states that this 


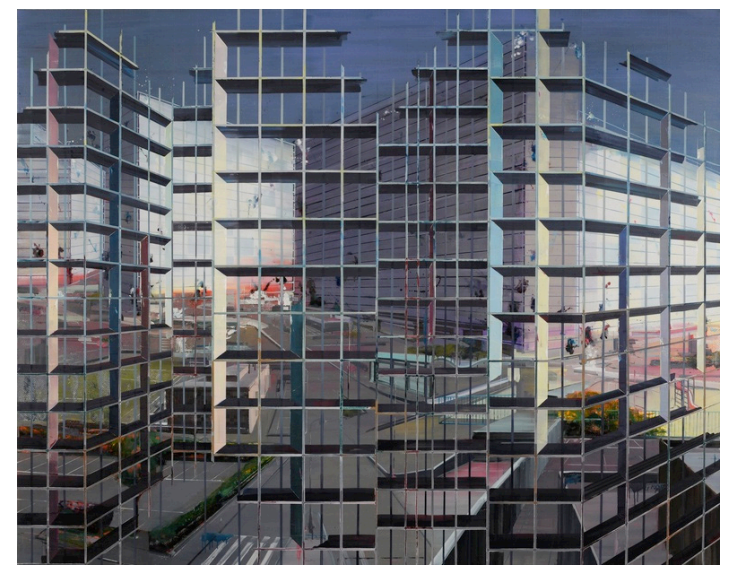

Driss Ouadahi, Toutes directions, 2011, oil on canvas, $190 \times 240 \mathrm{~cm}$. Screen capture. 16 October 2017. http://www.lawrieshabibi.com/exhibitions/14/works/image172/slide/

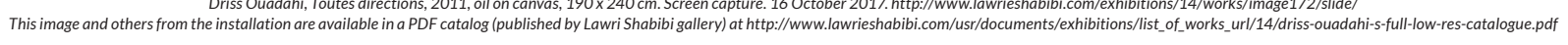

transcended space gives the Maghrebi immigrants an original form of representation, a purified form which would "reflect [their] experiences, while constantly exploring [their] own identity" (Oudahi). His paintings allow viewers to not only understand the trapped feelings of Maghrebi immigrants in Europe, but also experience the helplessness created by the intimidating architectural structures, from the border fences that separate families to the tall suburban housing projects that minimize immigrants' positions in European society.
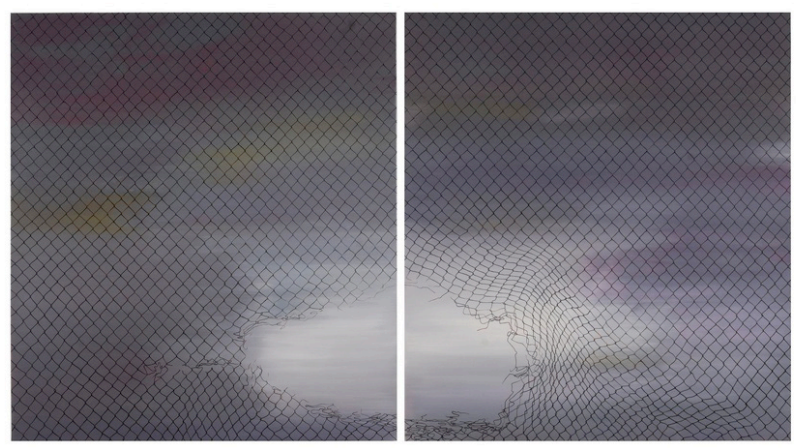

Driss Ouadahi, "Another Way." 2012. Oil on canvas, dyptich. 200 × 360 cm. Screen capture 16 October 2016. http://www.lawrieshabibi.com/exhibitions/14/works/image178/slide/

This image and others from the installation are available in a PDF catalog (published by Lawri Shabibi gallery) at http://www.lawrieshabibi.com/usr/documents/exhibitions/list_of_works_url/14/driss-ouadahi-s-full-low-res-catalogue.pdf

The collective culture of art of the Maghrebi Diaspora represents displacement in different ways, as Bouchra Khalili and Driss Ouadahi demonstrate with their contrasting spatial applications. Similarly, artists and writers differ in the ways they transform motifs of displacement into feelings of guilt and nostalgia. Yto Barrada, in The Strait Project, paints the Strait of Gibraltar as a physical space that carries the Maghrebi immigrants across the sea and disposes of their nationality in the process. The Strait Project is Barrada's avenue for portraying the "survivor's guilt" that immigrants carry once they settle in Europe. She provides two viewpoints of the strait; the first is the Spanish viewpoint, where Europeans see the strait as a passageway into a place of tourism and travel, while the second is the Moroccan viewpoint from Tangier, where Moroccans see the strait as a cemetery where the dreams of reconstructing Tangier have died with the people who have tried to cross it. In her personal statement about The Strait Project, "A Life Full of Holes," she states how Moroccans do not consider people leaving as "emigration," but rather say that they have "burnt," representing all of the lost hope that they carried with them. She 
writes, "[a] enclave long forgotten by national investments, Tangier is now the city where thousands of hopes come up short" (Barrada, "A Life Full of Holes"). Barrada portrays immigrants' guilt in a way that reflects a longing for the past which is overshadowed by a repetitive necessity to simultaneously change it, demonstrating how while immigrants long for their homeland, they also strive toward a future away from it.

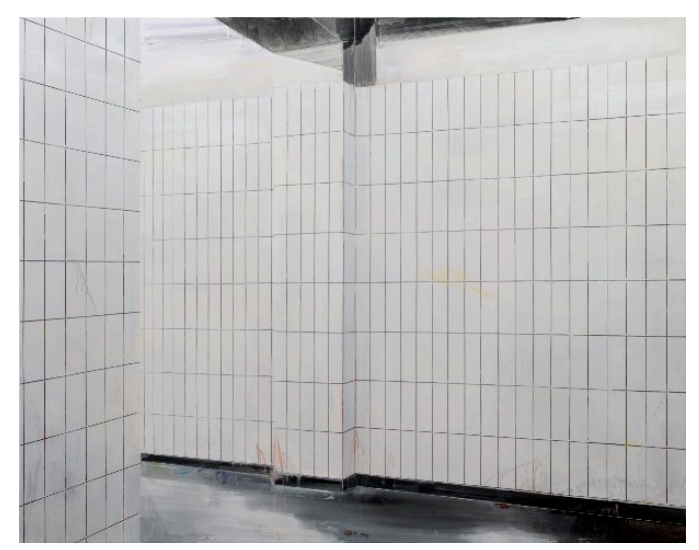

Driss Ouadahi, "Underground Path." 2010. Oil on canvas, 190 x 240 cm. Screen capture 16 October 2016. http://www.lawrieshabibi.com/exhibitions/14/works/image179/slide/

Survivor's guilt works in various ways, and just as Barrada elicits guilt within the immigrants for leaving their homelands, Moufida Fedhila places the burden of guilt on one's nationality. In her mixed media piece, In You We Trust, Fedhila portrays the fallen sanctity of the Tunisian flag by cutting out the crescent moon and the star, the symbol of Islam, from the center. Contrary to Barrada, Fedhila portrays Maghrebi immigrants' guilt as a form of resentment toward a government and religion meant to protect its people's interests. Nancy N.A. Demerdash writes how the rupture of trust creates an identity crisis and challenges Maghrebi views of patriotism, writing, "identity both collective and individual - are called into question. If trust is placed in the nation-state, this piece gestures at the loss of such trust, into an utterly vacuous void, leading nowhere" (Demerdash 263). As these immigrants travel across the sea, they burn a past identity, just as Barrada portrays; however, instead of showing a longing for one's home, Fedhila illustrates a collective resentment towards that home.

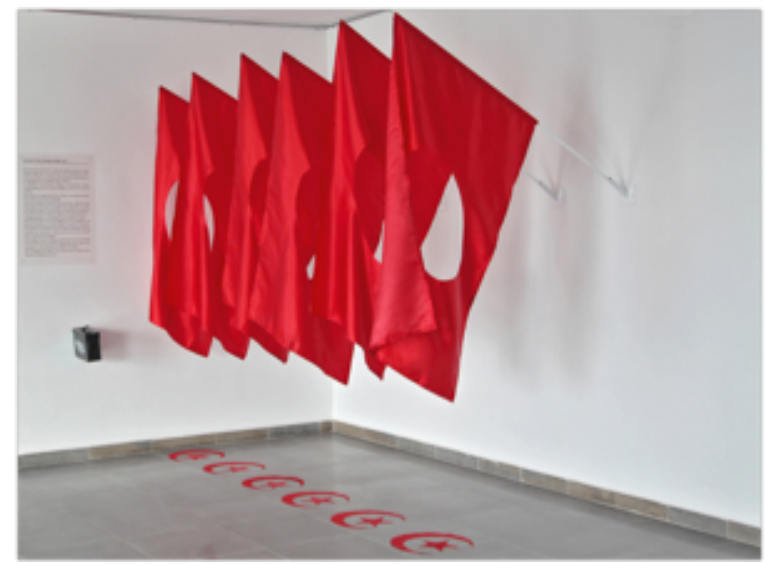

Moufida Fedhila, In You We Trust (2011-2012), Mixed Media installation. Exhibition view from "Ouverture," Bchira Art Center, Tunis/ "Rosy Future," Berlin. Screencapture from the artist's website. 16 October 2017. https://www.moufidafedhila.com/in-you-we-trust 
Scholars and writers have inputted the guilt narrative into storylines to help readers understand both perspectives of the guilt spectrum. In Tahar Ben Jelloun's The Happy Marriage and Leaving Tangier, he displays guilt as a product of nostalgia and of resentment through the progression of different characters. In The Happy Marriage, a husband and wife from different parts of Morocco who now live in Paris struggle with finding their identities as Maghrebi immigrants in Europe. The husband, a renowned painter, has assimilated into French culture. He paints pieces inspired by prominent French painters such as Eugene Delacroix. However, he repeatedly returns to Casablanca to sell these paintings. This process eventually feeds his guilt until finally he has a dream that people are yelling at him because they believe he writes novels in French instead of Arabic. Ben Jelloun demonstrates the nostalgia-driven guilt that Barrada writes about, noting, "I try to reason with them, to defend the right of those who write in French even though I'm not a writer, but I can feel their hatred" (Ben Jelloun, 63). The painter's dream symbolizes his hopes to fill the holes he leaves in Casablanca when he moves to France, hopes that he had burned when he left. Additionally, his inability to defend the Moroccan authors who write in French relays his admittance that he himself has lost touch with his Moroccan roots. The wife, on the other hand, experiences a different type of guilt, one which stems from her resentment toward Morocco's Arab supremacy. She was sold to a French family when she was a child, and resents her heritage because it has constantly put her in a lower position in society. Upon leaving for France, she vows to never return, noting, "I shut my eyes and decided I would never think about that unhappy village ever again" (230). This dynamic barely changes when she and her new family move to France, as the French people change her name to rid her of the stigma attached to her Amazigh identity. She longs to be back with her family, noting, "That city felt like a prison to me. It was ugly, gray, and stifling. I wanted so badly to leave it and never return" (233). However, she does not long to be back in Morocco. She sees her village as a place with proper and familiar values but sees Morocco as a place that has repressed those values. Her constant resentment toward her husband and her marriage derives from his treatment of her, reflective of the blatant discrimination of Amazigh people by the majority of Arab Moroccans.

Ahmed Idrissi Alami addresses the same feeling of guilt as a product of resentment in Ben Jelloun's Leaving Tangier, in which a young gay man named Azel from Morocco migrates to Spain and develops an interest in a wealthy Spanish man named Miguel. Though both of the men are gay, Azel is treated much differently, subjected to violence that stems from a xenophobic, European point of view and a hyper-masculine Moroccan point of view. This leads Azel to examine the oppressive structures that he is put under in both his homes. Alami notes how Ben Jelloun differentiates the views toward European and Moroccan homosexuals that the Europeans in the novel carry, writing how in Ben Jelloun's work, "the foreigner is constructed first and foremost as the homosexual to be despised" (Alami, 3). Additionally, Azel's progression toward self-acceptance helps readers visualize his battle with virility and sexual dominance in Moroccan culture, a force meant to degrade other men of lesser power. Alami writes, "[this novel] critiques the violent sexual power associated with virility and sexual dominance and perpetuated by men against men within Moroccan culture itself" (3). The two forms of treatment toward Azel demonstrate the dual concepts of guilt portrayed by artists like Yto Barrada and Moufida Fedhila. In one circumstance, Azel is not content with his position in Spanish society as he undergoes violent encounters with the local police and inherent discrimination in social settings, while in another he resents the hyper-masculine and sexually violent structures in Morocco that constantly emasculate him and repress his sexual identity.

The combination of displacement and guilt composes a psyche that constantly changes and adapts to different environments, leading Maghrebi immigrants to not know who they are or where to call home. They constantly receive attacks from outside cultures and subsequently deliver those attacks to indigenous populations, such as in The Happy Marriage. As they lose their homelands and the national identities attached to them, they search for an identity of their own, a new identity pursued by the contemporary art of the Maghrebi Diaspora, in a "transcended space" that Driss Ouadahi encourages immigrants to reach. The motif of displacement and guilt present in diasporic art and literature outline a common search for identity experienced in other parts of the West, specifically Latin America. Nancy N.A. Demerdash alludes to the world-renowned Mexican author, Gloria Anzaldua, citing a passage from her boo, Borderlands: La Frontera, in which she coins the phrase "mestiza consciousness." The mestiza consciousness is a product of "ambivalence from the clash of voices," resulting in "mental and emotional states of perplexity" (Anzaldua, 100). In La Frontera, Anzaldua proposes a solution to the mestiza's search for identity, calling for Latin Americans to develop a tolerance for ambiguity, to participate in the creation of a new culture through revolution, to develop a new form of machismo, or "macho," that dignifies femininity, and 
and to eliminate the fear of racial hatred (100-113). Similar to the mestiza, the Maghrebi immigrant remains confused, trying to blend traditions from one's homeland with the culture of the West while also being too afraid of hatred from westerners. These sources of confusion and fear eliminate the boundaries that maintain singularity in one's identity. As Anzaldua writes, "rigidity means death... [la mestiza] learns to juggle cultures. She has a plural personality, she operates in a pluralistic mode-nothing is thrust out, the good the bad and the ugly, nothing rejected, nothing abandoned. Not only does she sustain contradictions, she turns the ambivalence into something else" (101). Anzaldua's proposal applies universality to the experience of Maghrebi immigrants in Europe. Her ideas in La Frontera provide a foundation for artists who are attempting to help Maghrebi immigrants reach the "transcended space" in a way similar to how Anzaldua is helping Latin Americans develop the "mestiza consciousness."

Bouchra Khalili intertwines Anzaldua's proposal with the creation of a new Maghrebi immigrant identity in her Garden Conversations project. Her project focuses on the "retracing and reimagining" of revolutionary ideals in the Maghreb from the past (Nawi 4). The project pushes for a continuity of anti-colonial revolution in the Middle East, juxtaposing the ideas of Muhammad Abdelkarim al-Khattabi and Che Guevara, as well as visualizing how their legacies have become skewed over time in similar ways. Khalili alludes to the progress that Latin American communities have undergone as a result of implementing these revolutionary strategies; in addition, she asks Maghrebi immigrants to retrace the legacy created by al-Khattabi in order to step out of the oppressive state of confusion they live in and create a new identity that merges their traditions from the Maghreb with the values they have adopted in the west.

The universality of the guilt and loss of identity experienced by Maghrebi immigrants allows for the contemporary art of the Maghrebi Diaspora to have tangible effects on the world. Its conception offers an avenue for Maghrebi immigrants to represent their unique experiences as a collective body. In order to help people understand the lasting effects of displacement on large populations, artists such as Driss Ouadahi, Bouchra Khalili, Yto Barrada, and Moufida Fedhila, as well as authors and scholars such as Tahar Ben Jelloun and Gloria Anzaldua, manipulate the preconceived expectations of viewers by visualizing feelings of geographic displacement, claustrophobia and separation, nostalgia and resentment-driven guilt, and a never-ending search for a cultural identity. 


\section{WORKS CITED}

Alami, A. I. "Dialectics of Desire, Victimhood and Postcolonial Migrancy in Tahar Ben Jelloun's Leaving Tangier." South Central Review. 30.2 (2013): 1-31. Project MUSE. doi:10.1353/scr.2013.0012.

Anzaldua, Gloria. Borderlands/La Frontera: The New Mestiza. 1987. 3rd ed. San Francisco: Aunt Lute. 2007. Print.

Barrada, Yto. "A Life Full of Holes - The Strait Project." Warwick Arts Centre. Retrieved from http://www.warwick artscentre.co.uk/mead-gallery/previous-exhibitions/2005/yto-barrada-a-life-full-of-holes-the-strait-project/

Demerdash, Nancy N. A. "Bordering Nowhere: Migration and the Politics of Placelessness in Contemporary Art of the Maghrebi Diaspora." Journal of North African Studies 21.2 (2016): 258-72. Humanities International Index. Web. 1 Nov. 2016. doi:http://dx.doi.org/10.1080/13629387.2016.1131953

Jelloun, Tahar Ben. The Happy Marriage: A Novel. Translated by André Naffis-Sahely. Brooklyn: Melville House. 2016. Print.

Nawi, Diana. “Other Maps: On Bouchra Khalili’s Cartographies.” Ibraaz. 008. 15 January. http://www.ibraaz.org/es says/115

Triki, Rachida. Interview with Driss Quadahi. "If Walls Could Talk:” Driss Quadahi in Conversation with Rachida Triki." Ibraaz. 003. 24 May 2012. Web.http://www.ibraaz.org/interviews/27 